\title{
RAIINSTEK
}

\section{PENGEMBANGAN HOTSPOT SERVER BERBASIS MIKROTIK DI DESA REMBUN KEC. DAMPIT KAB. MALANG}

\author{
Windy Syarifudin ${ }^{1}$, Akhmad Zaini ${ }^{2}$, Danang Aditya Nugraha ${ }^{3}$ \\ Teknik Informatika Universitas Kanjuruhan Malang 1, 2, 3 \\ Email: the.wyndie@gmail.com
}

\begin{abstract}
Abstrak. Desa Rembun yang terletak pada koordinat 8¹1'38.9436" S$112^{\circ} 42$ '43.5744" E merupakan salah satu desa dengan kondisi geografis yang memiliki topografi perbukitan sehingga aksebilitasnya sedikit sulit terutama akses jaringan $4 \mathrm{G}$. Belum meratanya akses jaringan $4 \mathrm{G}$ di pedesaan menjadikan pengguna yang ingin merasakan akses jaringan $4 \mathrm{G}$ harus mendatangi beberapa tempat yang sudah tersedia jaringan $4 \mathrm{G}$. Untuk mengatasi permasalah tersebut perlu disediakan distribusi jaringan indihome melalui manajemen bandwidth dengan menggunakan Mikrotik RouterBoard. Untuk dapat mengetahui pengelolaan atau manajemen bandwidth pada access hotspot, dari hasil uji bandwidth yang telah dilakukan jaringan hotspot ini memiliki peluang untuk bisa melayani 80 pengguna pada setiap titik distribusi dengan asumsi tiap pengguna mendapat jaminan bandwidth sebesar 1 Mbps.
\end{abstract}

Kata Kunci: Jaringan, Hotspot, mikrotik, manajemen bandwidth

\section{PENDAHULUAN}

Pada era globalisasi sekarang internet merupakan kebutuhan yang tidak dapat terlepaskan dari semua aspek kehidupan masyarakat modern. Fasilitas internet juga dapat membantu kehidupan masyarakat baik untuk berkomunikasi maupun berbisnis. Kendala yang terjadi berkaitan dengan teknologi internet adalah belum meratanya akses internet dibeberapa wilayah seperti wilayah daerah pedesaan khususnya daerah yang memiliki medan yang sangat variatif dan jauh dari pusat kota. Desa Rembun yang terletak pada kordinat $8^{\circ} 11^{\prime} 38.9436^{\prime \prime} \mathrm{S}-112^{\circ} 42^{\prime} 43.57744^{\prime \prime}$ E yang merupakan salah satu desa dengan kondisi geografis dengan topografi perbukitan sehingga aksebilitasnya sedikit sulit salah satunya adalah akses jaringan 4G atau jaringan mobile. Untuk mengatasi permasalahan terbatasnya jaringan mobile, peneliti membuat sebuah distribusi jaringan melalui jaringan indihome melalui manajemen bandwidth dengan menggunakan Mikrotik RouterBoard sebagai server sehingga tagihannya bisa ditanggung bersama.

Jaringan komputer merupakan kumpulan beberapa perangkat seperti switch, printer, speaker, keyboard, dan mouse dan banyak perangkat yang bisa saling terhubung melalui media perantara berkabel atau nirkabel (Sofana,2008). Ada beberapa perangkat yang bisa saling terhubung untuk berbagi banyak hal seperti data dan koneksi internet.

Hotspot merupakan lokasi geografis tertentu dimana titik akses menyediakan layanan jaringan broadband nirkabel untuk pengunjung melalui WLAN, seringkali terdapat ditempat keramaian seperti mall, stasiun, perpustakaan, dan cafe (Oei,2015). Hotspot biasanya hanya memiliki jangkauan akses beberapa meter saja. Banyak masyarakat yang menyebut jika pada suatu tempat terdapat internet yang disebarkan maka itulah yang dinamakan hotspot, sedangkan hotspot yang ada pada mikrotik adalah sebuah sistem untuk memberikan fitur autentikasi pada client yang akan mengakses pada suatu jaringan dan bila ingin mengakses jaringan tersebut pengguna atau client harus memasukkan username dan password pada loginpage yang sudah disediakan 
RouterBoard merupakan sebuah perangkat lunak dan sebuah sistem operasi yang dapat digunakan untuk memfungsikan komputer sebagai router. Router juga dilengkapi dengan beberapa fasilitas dan alat untuk jaringan berkabel dan nirkabel. Mikrotik dikenal dengan kestabilan, kualitas kontrol dan fleksibilitas untuk berbagai paket data dan penanganan proses routing (Gunawan,2018).

Berdasarkan definisi tersebut makna manajemen bandwidth dapat diartikan sebagai kegiatan mensetting agar data yang dilalui tidak melebihi kapasitas maksimal yang ditentukan didalam sebuah jaringan komputer yang terhubung dengan internet. Semakin banyak client komunikasi data, maka semakin rumit jalur komunikasi data tersebut, hal ini akan sangat mempengaruhi nilai dari pelayanan Internet Service Provider (ISP) (Mujahidin,2011)

\section{METODE PENELITIAN}

Penelitian tentang jaringan komputer menggunakan mikrotik router sebagai server, diperlukan suatu metode rancang bangun agar pelaksanaan dapat terencana dan berjalan dengan baik. Metode yang dilaksanakan tergambar pada gambar 1. Flowchart rancangan jaringan.

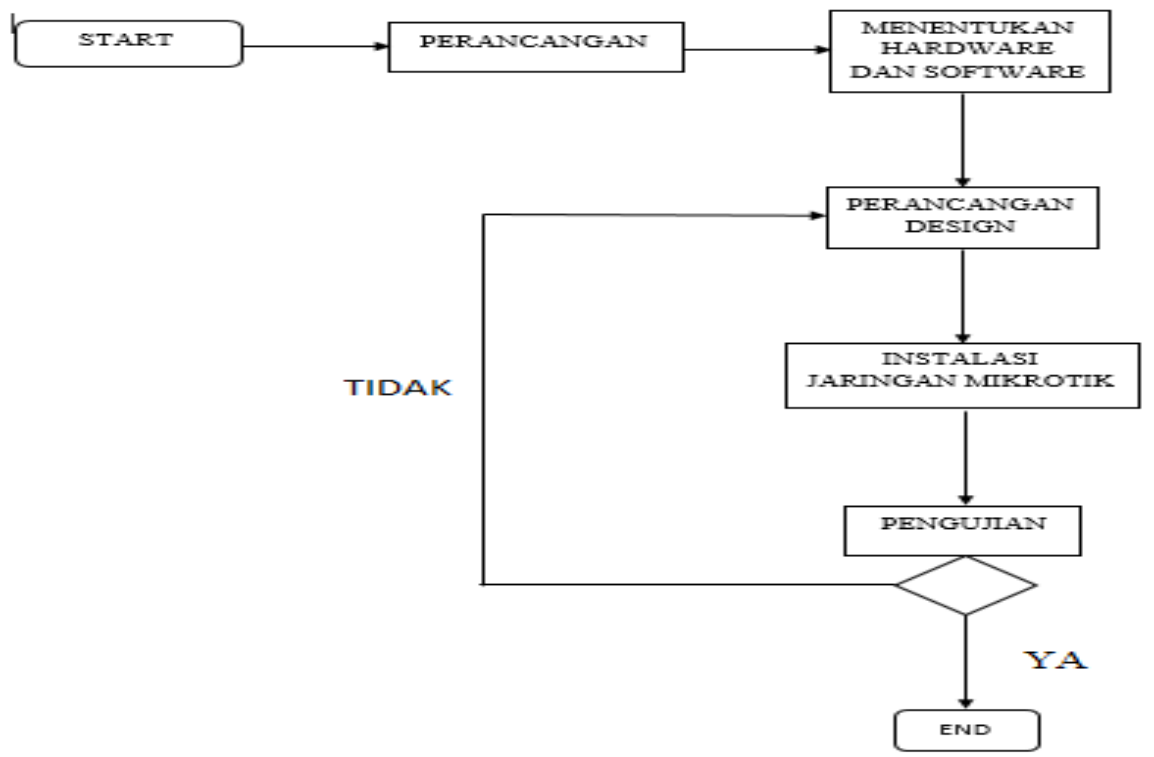

Gambar 1. Flowchart rancang bangun

Tahapan perancangan yang dilakukan sebagai berikut:

Perancangan dimulai dari perencanaan dengan melakukan survei lokasi perkiraan penempatan perangkat Access Point utama dan Access Point client di Desa Rembun. Setelah dilakukan perencanaan maka tahap selanjutnya adalah implementasi penentuan tempat Access Point utama dan Access Point client 


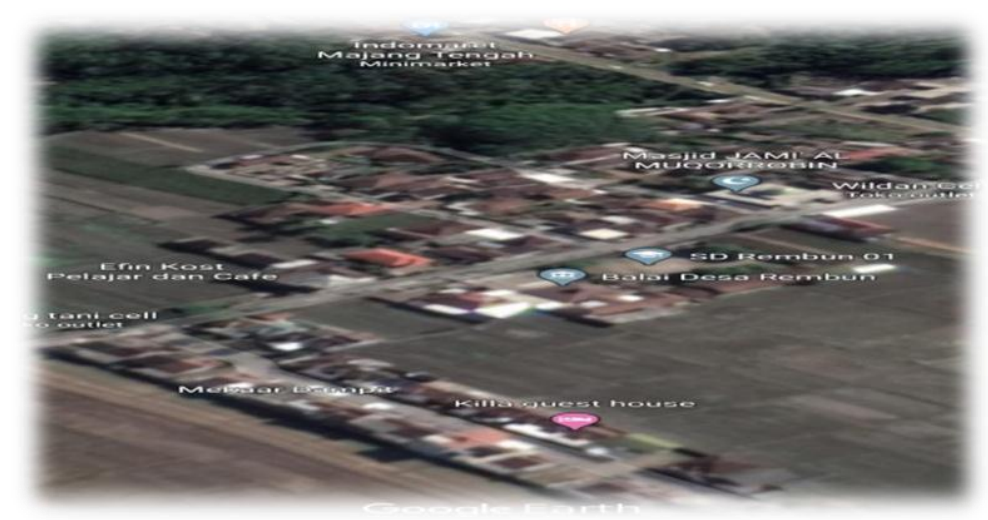

Gambar 2. Implementasi alat

Penentuan Hardware dan Software

- Laptop yang akan digunakan sebagai konfigurasi

- Mikrotik RouterBoard digunakan sebagai konfigurasi hotspot dan administrator

- TP-Link sebagai perangkat yang akan menyebarkan sinyal atau frekuenzi ke client

- Access Point digunakan sebagai penghubung antara jaringan utama dengan jaringan client.

- Kabel UTP digunakan sebagai penghubung beberapa perangkat

- Winbox aplikasi yang digunakan untuk memudahkan konfigurasi dengan mode GUI dengan cepat dan tampilan sederhana

- Google chrome digunakan sebagai media konfigurasi perangkat ketika masuk kedalam firmware perangkat

Perancangan Design. Komponen utama yang saling berhubungan yaitu akses ISP (Internet Service Provider), modem, Access Point utama yang akan terhubung dengan Access Point client menggunakan metode distribusi Point to Point, dan Mikrotik RouterBoard akan memanajemen bandwidth ke setiap client

Instalasi jaringan Mikrotik. Proses yang dilakukan adalah potong kabel UTP, penyambungan kabel UTP ke konektor RJ45, perakitan jaringan dengan menyatukan komponen-komponen jaringan komputer baik komponen utama maupun komponen penunjang.

Pengujian: Point to Point merupakan pengujian terhadap eksistensi SSID Access Point Bridge terhadap Access Point Stasion.

Routing dilakukan dalam 2 pengujian. Pengujian pertama routing dari server menuju internet dan pengujian kedua dari client menuju server dan internet dengan menggunakan perintah traceroute Bandwidth dan throughput dilakukan untuk menganalisa paket data yang dikirim dan diterima antar perangkat. Packet Loss dan Latency sebagai gambaran berapa jumlah paket yang hilang karena tabrakan.

\section{HASIL DAN PEMBAHASAN}

Perancangan Design. Berdasarkan hasil identifikasi dilapangan, pengamatan dan penerapan letak Access Point pada Desa Rembun maka dapat direncanakan sebuah jaringan Hotspot berbasis Mikrotik.Desa Rembun memiliki Dua unit Access Point dengan jarak antar perangkat \pm 500 meter yang terpasang pada tiang khusus. Koneksi antar perangkat Access Point ini menggunakan jaringan wireless dengan frekuensi $5.8 \mathrm{Ghz}$ agar mengurangi interupsi. 


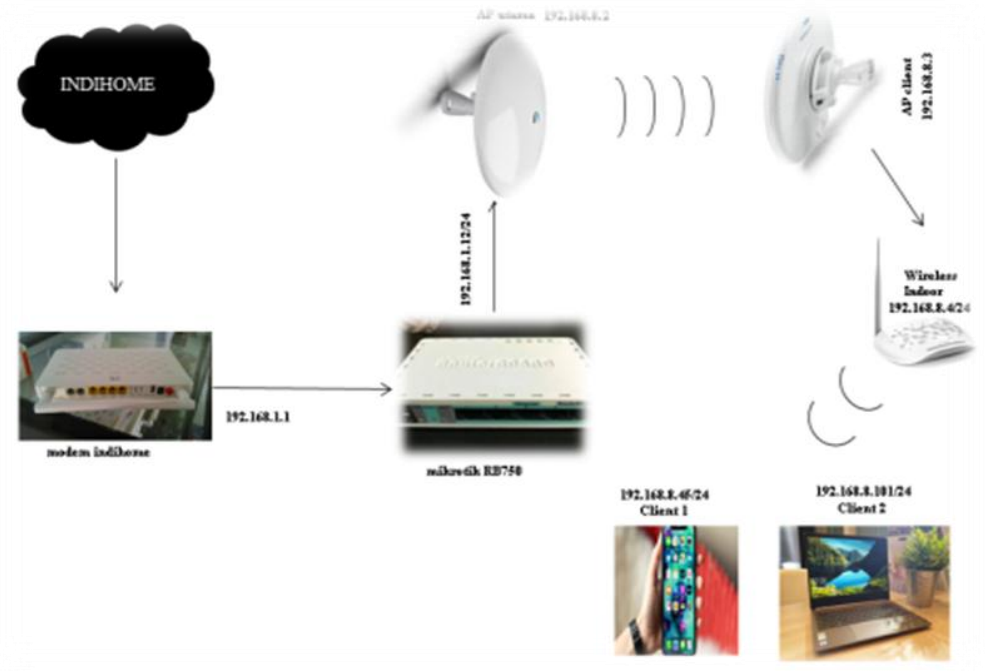

Gambar 3. Topologi

Instalasi Jaringan Mikrotik

Sebelum melakukan proses konfigurasi Mikrotik adalah pengerjaan potong kabel UTP, penyambungan kabel UTP ke RJ45 dan disambungkan ke perangkatperangkat yang akan diimplementasikan.

Pada umumnya RouterBoard mikrotik sudah terdapat konfigurasi awal yang sudah siap pakai, tetapi konfigurasi bawaan RouterBoard mikrotik terkadang tidak sesuai yang diinginkan administrator

Proses potong dan penyambungan kabel UTP ke RJ45 proses ini harus dilakukan dengan teliti karena jika terjadi kesalahan maka perangkat yang akan digunakan akan tidak dapat terhubung dengan baik
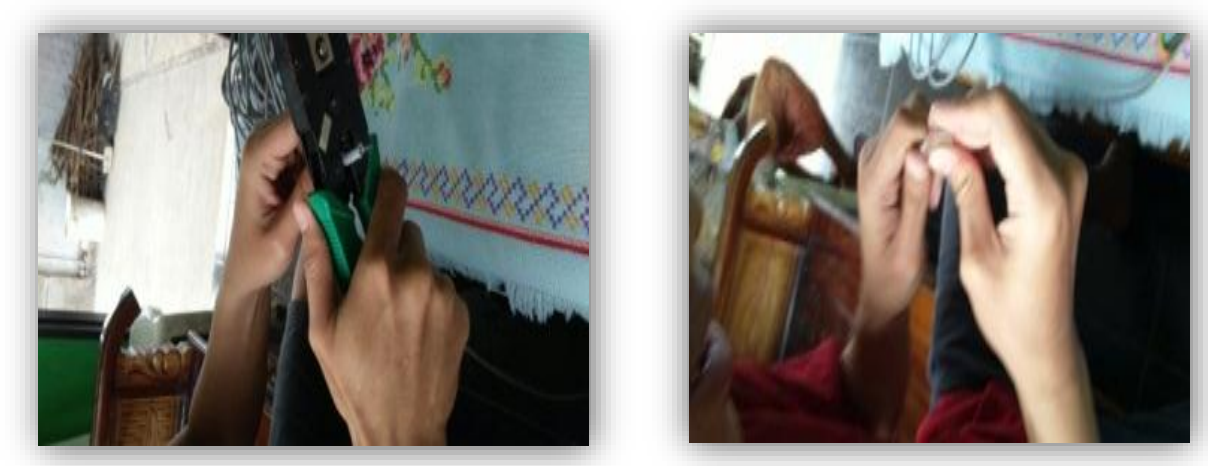

Gambar 4. Proses potong kabel dan penyambungan kabel UTP ke RJ45

Selanjutnya penamaan interfaces yang bertujuan agar administrator memahami inisialisasi masing-masing ip dengan nama yang berbeda pada gambar dibawah menjelaskan untuk Etherl ADSL yang tersambung dari modem ke RouterBoard dan Ether2 Hotspot yang tersambung dengan Access Point utama. 


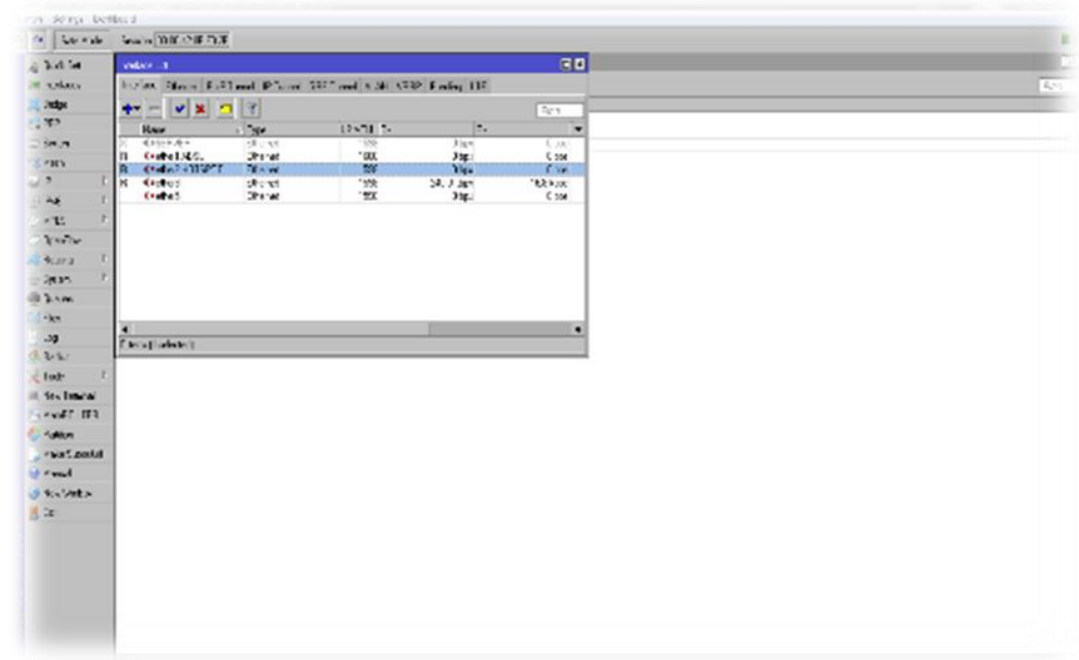

Gambar 5. Penamaan interfaces

Proses selanjutnya adalah setting ip yang akan digunakan untuk masingmasing Ethernet. Untuk Etherl ADSL interfaces yang digunakan sebagai jalur dari modem menuju mikrotik menggunakan IP Address 192.168.1.12/24 dan untuk Ether2 Hotspot interfaces yang digunakan sebagai jalur dari mikrotik menuju Access Point yang nanti gunakan sebagai hotspot menggunakan IP Address 192.168.8.1/24.

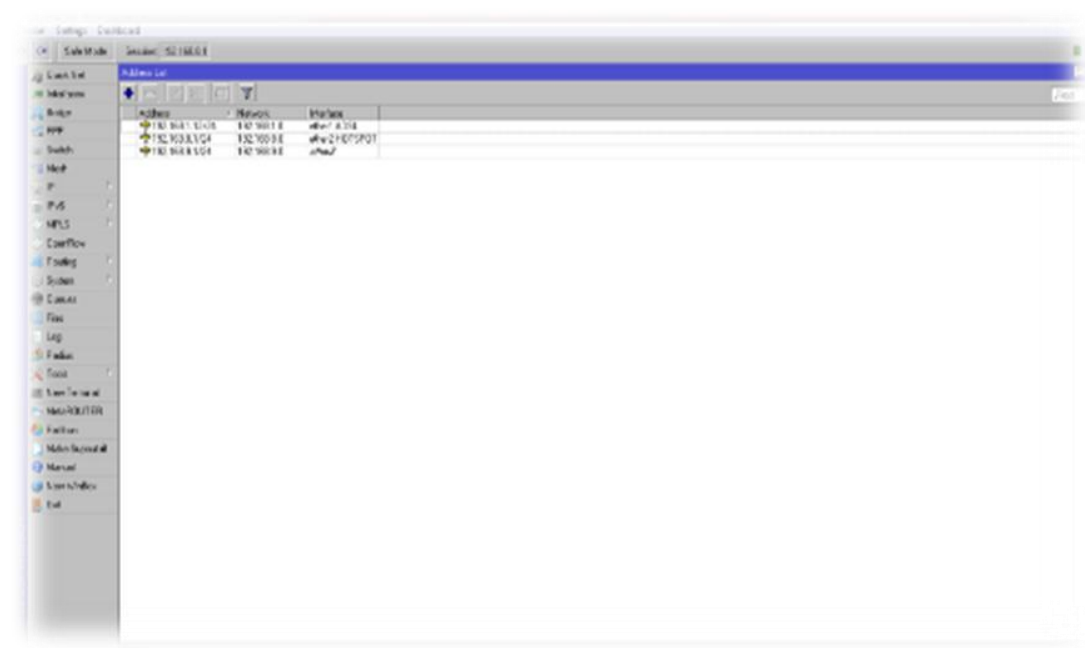

\section{Gambar 6. Address list}

Setting NAT yang berfungsi agar client dibawah Router dapat mengakses internet meskipun tidak tergabung dalam jaringan sehingga jaringan client tidak bisa langsung mengakses dashboard Indihome. 


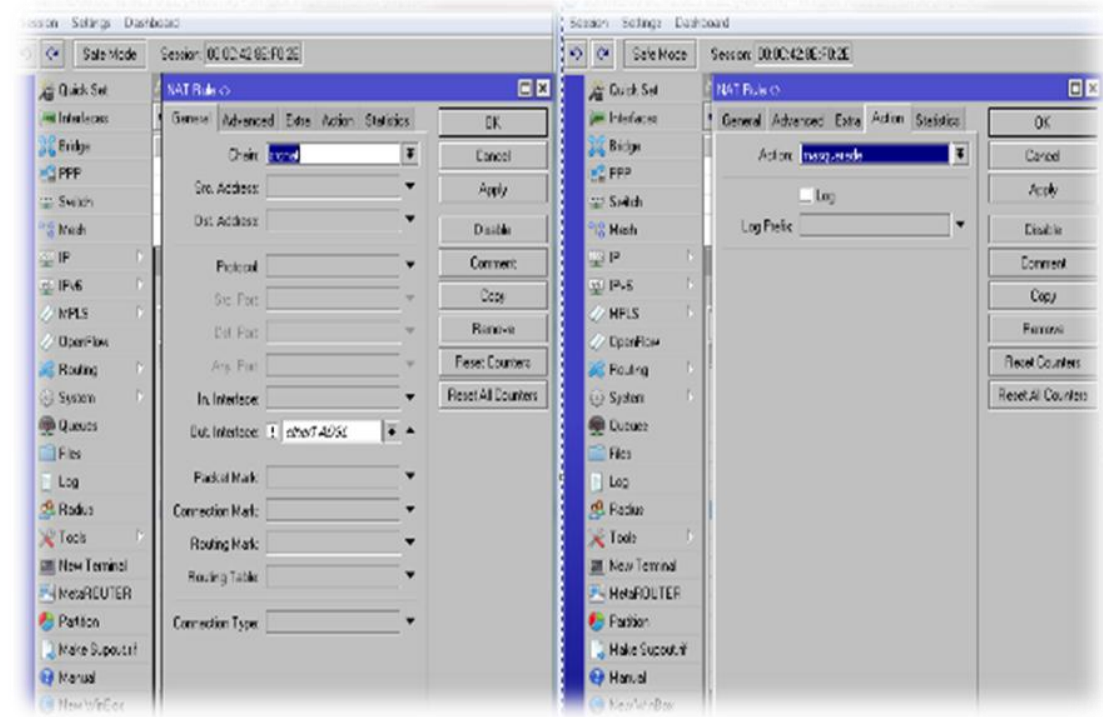

Gambar 7. Setting NAT

Konfigurasi Hotspot

Tahapan konfigurasi hotspot ini menggunakan aplikasi winbox dengan menggunakan aplikasi ini administrator akan mudah saat konfigurasi dengan dituntun menampilkan dialog pada setiap langkahnya.

1. Pilih interfaces mana yang akan diaktifkan Hotspot servernya. Setiap interfaces yang dipakai akan ditandai dengan nama dan IP Address. Pada penelitian ini interfaces yang digunakan hotspot diberi nama Ether2 HOTSPOT yang terkoneksi dengan Access Point utama dan menggunakan IP Address 198.168.8.1/24 dengan network 192.168.8.1

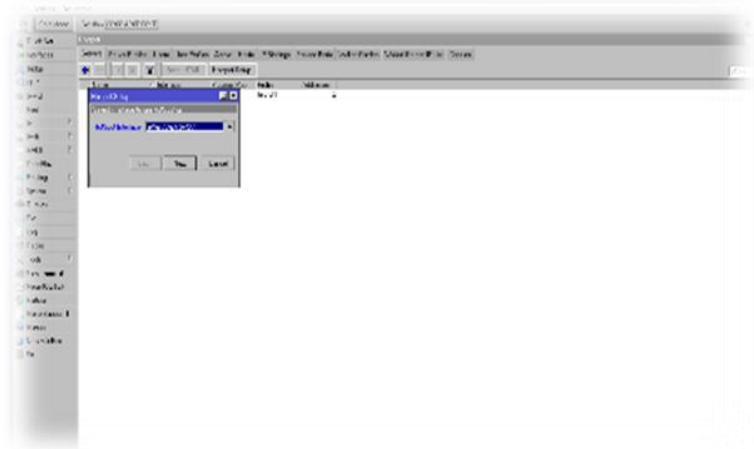

Gambar 8. Hotspot Interfaces

2. Langkah terakhir adalah menentukan username dan password untuk login ke jaringan hotspot yang telat dibuat. Pada penelitian ini username yang digunakan untuk mencoba jaringan hotspot dan setting sampai muncul dialog bahwa setting hotspot telah berhasil dan pada penelitian ini dibuat 2 username.
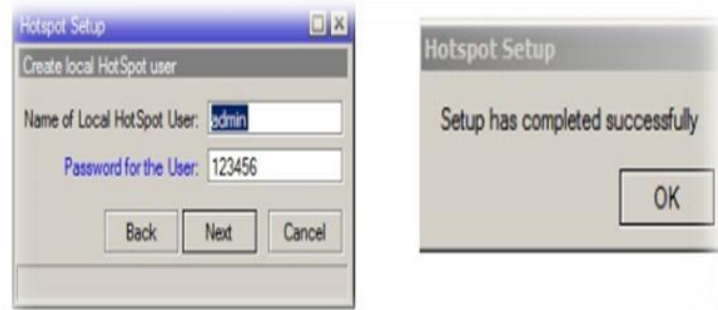

Gambar 9. Setting username dan password 


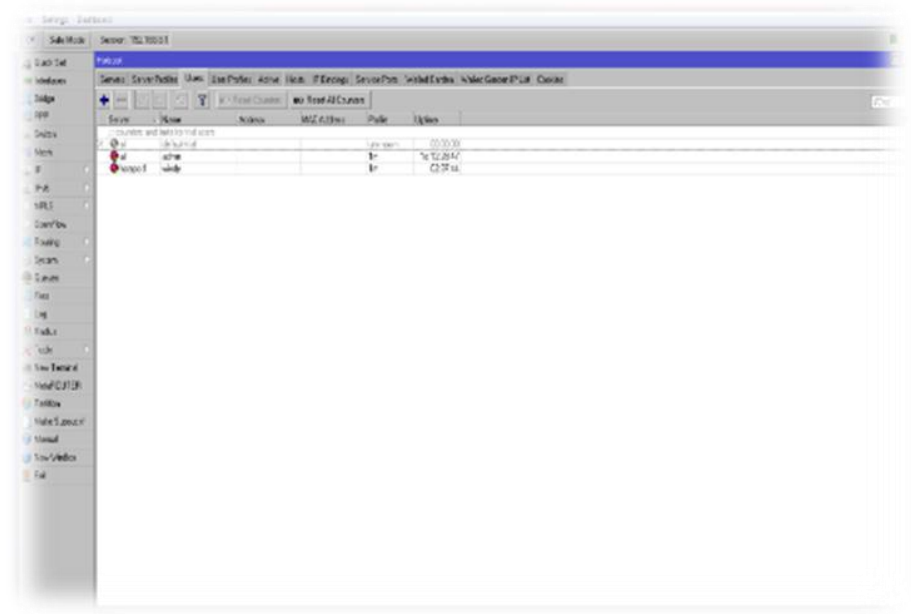

Gambar 10. Total username

Pengujian

Dalam membangun sebuah sistem jaringan penelitian ini menggunakan metode pendistribusian point to point. Karena letak geografis penelitian ini yang sangat tidak memungkinkan untuk menarik kabel dari jaringan utama ke jaringan client. Dengan pendistribusian metode point to point pada sisi Access Point utama menggunakan mode brigde dan pengaturan band, SSID, dan frekuensi yang disesuaikan dengan kebutuhan. Sedangkan pada sisi Access Point client menggunakan mode Station dan pengaturan SSID dan band yang disesuaikan dengan Access Point.

1. Pengujian point to point dengan cara signal scaning dilakukan agar sinyal Access Point client dapat menemukan perangkat Access Point server. Terlihat eksistensi dari perangkat Access Point server dengan SSID windy Conection dan Signal atau Noisenya 44/-104

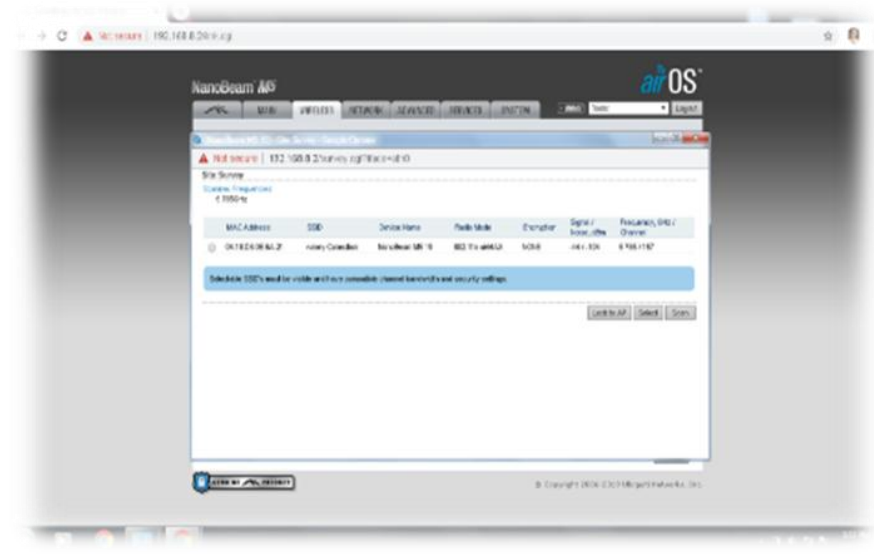

Gambar 11. Signal scanning

2. Pengujian routing dari station dan server menuju internet menggunakan perintah traceroute di CMD. Perintah traceroute untuk menunjukkan rute yang dilewati paket untuk mencapai tujuan, 


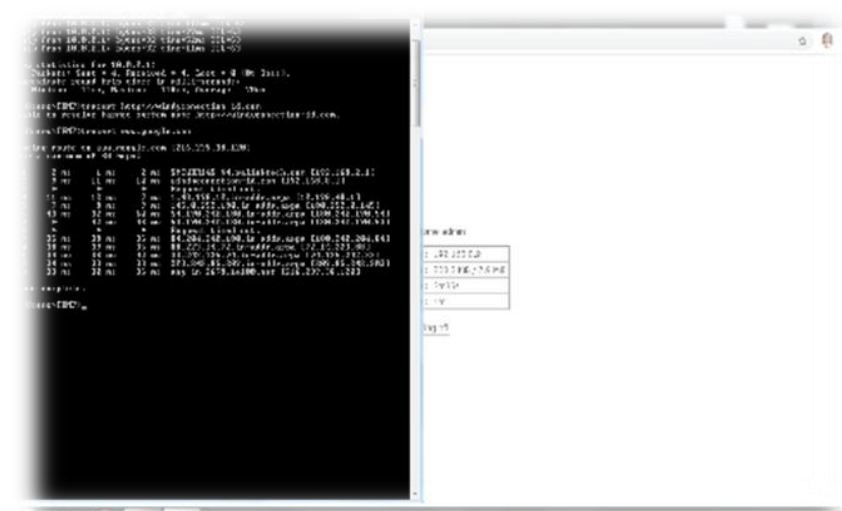

Gambar 12. Traceroute station ke internet
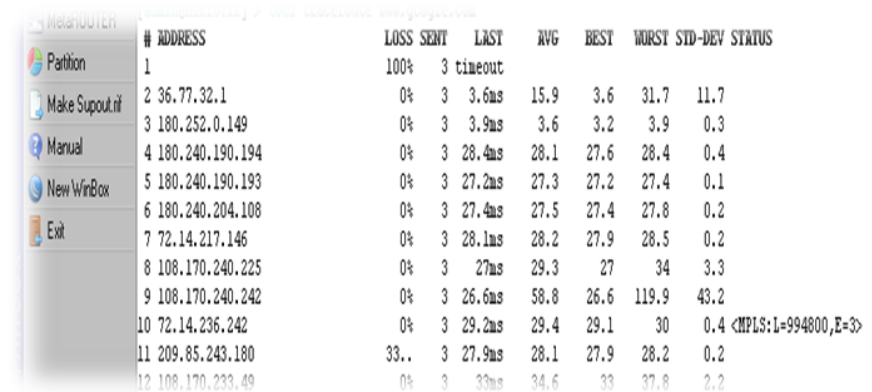

Gambar 13. Traceroute server ke internet

3. Pengujian bandwidth adalah pengujian jaringan utama atau jaringan backbone yang akan didistribusikan ke jaringan hotspot. Pengujian ini dilakukan untuk memastikan bahwa bandwidth jalur utama yang akan dijadikan layanan hotspot publik sudah cukup maksimal dan proses ini didapatkan dengan cara menscaning perangkat Access Point server melalui tolls speedtest yang tersedia di software airOS.

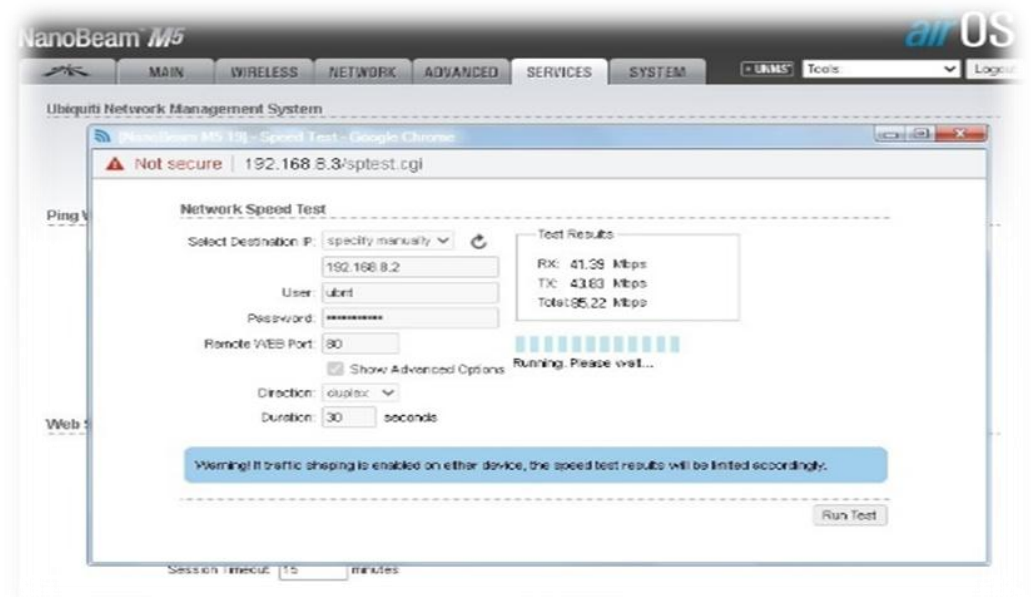

Gambar 14. Uji bandwidth point to point

4. Pengujian yang terakhir ada pengujian packet loss atau latency. Dalam pengujian ini diukur dengan menggunakan tes ping di Command Prompt. Latency dalam penelitian ini merupakan jumlah waktu yang dibutuhkan paket data untuk berpindah dari suatu jaringan dalam satuan millisecond ( $m s$. 


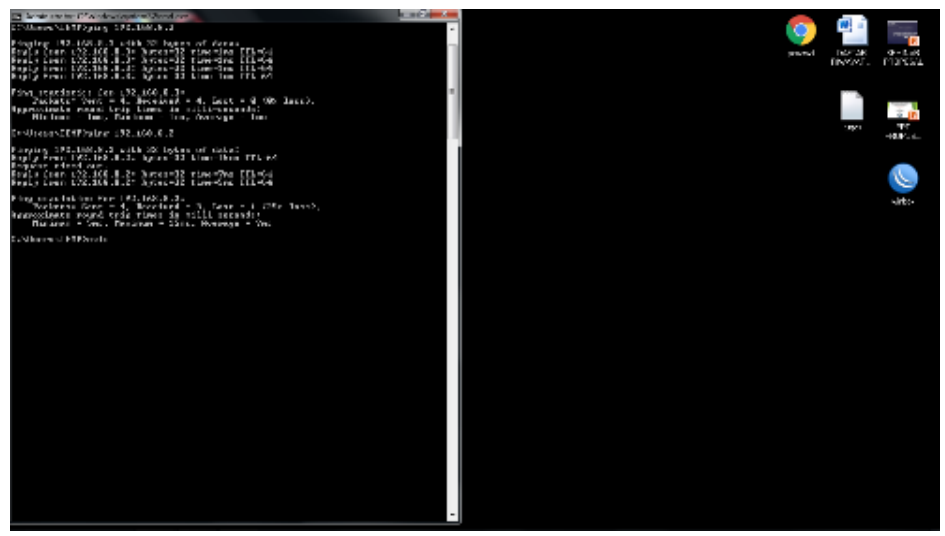

Gambar 15. Ping client ke Access point

\section{PENUTUP}

Kesimpulan dalam penelitian yang telah dilakukan adalah : 1). Layanan jaringan hotspot dapat disediakan dengan baik di Desa Rembun. Hal ini dapat dilihat dari hasil uji latency jaringan utama (backbone) point to point yang memiliki latency tidak terlalu tinggi yakni $15 \mathrm{~ms}$. 2). Total bandwidth point to point sebesar $85.22 \mathrm{Mb}$ dari hasil uji bandwidth yang telah dilakukan, jaringan hotspot ini memiliki peluang untuk bisa melayani 80 pengguna pada setiap titik distribusi. Dengan asumsi tiap pelanggan mendapat jaminan bandwidth sebesar $1 \mathrm{Mb}$. 3) Mikrotik Router mampu melakukan manajemen user pengguna hotspot, sehingga bandwidth yang diterima oleh user tidak berlebihan.

Saran untuk penelitian selanjutnya adalah : 1). Sistem hotspot dapat dikembangkan menjadi sistem yang terdistribusi, sehingga pengelolaan client hotspot tidak selalu berada dipusat. 2). Kapasitas bandwidth yang dimiliki oleh jaringan utama melebihi kapasitas koneksi broadband yang digunakan pada penelitian ini, sehingga bila menggunakan koneksi broadband dengan kapasitas lebih besar tentunya akan meningkatkan kualitas layanan hotspot. 3). Perlunya penambahan lebih banyak stasion agar layanan hotspot dapat menjangkau lebih banyak pengguna.

\section{DAFTAR PUSTAKA}

Afdhal, A., \& Elizar, E. (2014). IEEE 802.11 ac sebagai Standar Pertama untuk Gigabit Wireless LAN. Jurnal Rekayasa Elektrika, 11(1), 36-44

Alaydrus, Mudrik. Antena Prinsip dan Aplikasi. 2011. Graha Ilmu.Yogyakarta.

Sukamaaji A, Rianto. 2008. "Jaringan Komputer: Konsep Dasar Pengembangan Jaringan dan Keamanan Jaringan", Andi Publisher. Yogyakarta.

Ardiansa, G. F. E., Primananda, R., \& Hanafi, M. H. (2017). Manajemen Bandwidth dan Manajemen Pengguna pada Jaringan Wireless Mesh Network dengan Mikrotik. Jurnal Pengembangan Teknologi Informasi dan Ilmu Komputer e-ISSN, 2548, 964X.

Fitria, T. S., \& Prihanto, A. (2018). Implementasi Generate Voucher Hotspot Dengan Batasan Waktu (Time Based) Dan Kuota (Quota Based) Menggunakan User Manager Di Mikrotik. Jurnal Manajemen Informatika, 8(2).

Gunawan, H., Simorangkir, H., \& Ghiffari, M. Pengelolaan Jaringan Dengan Router Mikrotik Untuk Meningkatkan Efektifitas Penggunaan Bandwith Internet (Studi Kasus Smk Ki Hajar Dewantoro Kota Tangerang). 
Mujahidin, T. (2011). OS Mikrotik Sebagai Manajemen Bandwidth dengan Menerapkan Metode Per Connection Queue. Naskah Publikasi. Yogyakarta: Amikom.

Oei, S. (2015, July). Rancang Bangun Jaringan Hotspot pada Kampus Niversitas Nusantara Manado Menggunakan Router Mikrotik. In Seminar Nasional Informatika (SEMNASIF) (Vol. 1, No. 1).

Setiotirin, R. W. (2018). Strategi Komunikasi Pemasaran Indihome Melalui Aplikasi Mobile My Indihome (Studi Kasus di Direktorat Konsumer PT. Telekomunikasi Indonesia, Tbk). Idea: Jurnal Humaniora, 71-83.

Sofiana Iwan. (2008). Membangun Jaringan Komputer. Informatika. Bandung

Sujalwo, Sujalwo. "Manajemen Jaringan Komputer Dengan Menggunakan Mikrotik Router (Computer Network Management Used With Microtic Router)." Komuniti: Jurnal Komunikasi dan Teknologi Informasi 2.2 (2017): 32-43.

Sukri, J. (2017). Analisa Bandwidth Menggunakan Metode Antrian Per Connection Queue. Rabit: Jurnal Teknologi dan Sistem Informasi Univrab, 2(2), 136-151.

Lammle Todd. (2012). CompTIA Network + Study Guide 2nd Edition. Indianapolis: John Wiley \& Sons.

Ulfah, M., \& Irtawaty, A. S. (2018). OPTIMASI JARINGAN 4G LTE (LONG TERM EVOLUTION) PADA KOTA BALIKPAPAN. Jurnal Ecotipe (Electronic, Control, Telecommunication, Information, and Power Engineering), 5(2), 1-10.

Wardoyo, S., Ryadi, T., \& Fahrizal, R. (2014). Analisis performa file transport protocol pada perbandingan metode IPv4 murni, IPv6 murni dan tunneling 6to4 berbasis router mikrotik. Jurnal Nasional Teknik Elektro, 3(2), 106-117.

Yuniarti, R. (2009). Optimalisasi peralihan penggunaan teknologi wifi ke wimax. Tugas Akhir. 